Article

\title{
Precision Cutting of the Molds of an Optical Functional Texture Film with a Triangular Pyramid Texture
}

\author{
Huang Li, Zhilong $X u^{*}$, Jun Pi and Fei Zhou \\ College of Mechanical and Energy Engineering, Jimei University, Xiamen 361021, China; \\ li_huang6002@163.com (H.L.); Pi_jun@163.com (J.P.); zf18850043071@163.com (F.Z.) \\ * Correspondence: zhilongxu1@163.com; Tel.: +86-592-618-3501
}

Received: 10 January 2020; Accepted: 25 February 2020; Published: 27 February 2020

check for updates

\begin{abstract}
Based on an analysis of the precision and preparation technology of an optical texture film with a triangular pyramid texture, the technical requirements of the original mold were determined, and precision shaping planning technology was adopted to process the original mold. The shape error of the optical texture mold of the triangular pyramid was assessed by defining the area ratio of the retro-reflection. The influence of the tool nose radius and exit burr on the area ratio of the retro-reflection were analyzed. By optimizing the cutting tools, cutting materials and cutting boundaries, a five-axis ultra-precision machining system was used to plan the triangular pyramid structure with a base length of $115 \mu \mathrm{m}$ and an included angle between two sides of $70.5^{\circ}$. The experimental results indicate that the dimension error of the triangular pyramid element is less than $1 \mu \mathrm{m}$, the angle error of the included angle between two sides is less than $0.05^{\circ}$, and the average roughness of the side of the triangular pyramid can reach $9.2 \mathrm{~nm}$, which satisfies the processing quality requirements of the triangular pyramid texture mold.
\end{abstract}

Keywords: optical functional texture film; area ratio of retro-reflection; triangular pyramid texture; mold of light trapping film

\section{Introduction}

An optical functional texture film is a surface microarray film that can change the path of light propagation [1]. With its exceptional light conductivity and self-cleaning function, this texture film has attracted the attention of many researchers. With improvements in ultra-precision machining technology, the preparation of the optical functional texture of surfaces has become a popular research topic in precision machining. There are two classes of methods in preparing an optical functional texture film. One type of method involves directly preparing the optical functional texture on the surface of the work piece with technology, such as plasma etching [2] and lithography [3]. The other is to obtain the optical functional texture via embossing technology, such as hot embossing $[4,5]$ and ultraviolet (UV) imprinting [6,7]. In 2015, Rahman [8] et al. published in Nature Communications that three types of nanoscale tapered light-trapping textures were directly prepared on the surface of a poly(methyl methacrylate) (PMMA) thin film via plasma etching. The tapered light-trapping texture ranged from 10-70 $\mathrm{nm}$ in diameter, and the light absorption rate of the smooth crystal silicon cells was improved. Diao et al. [9] prepared moth-eye nanostructures with high transmission and anti-reflection on optical substrates via block copolymer micelle lithography (BCML) and reactive ion etching. Ion etching or photolithography can be used to directly prepare the optical functional texture with a high surface quality and machining accuracy. However, these methods demonstrate complex processing with a low processing efficiency and high manufacturing costs; thus, they are unsuitable for large-scale production and have remained only in the experimental research stage. 
An optical functional textured film was prepared by using embossing technology. First, a mold with texture was processed, and then the mold texture was embossed on the surface of an optical film [10]. This method has a high manufacturing efficiency and a low production cost and can be employed in mass production. According to the microstructural dimensions of the mold texture, the texture can be divided into nanoimprints and microimprints. The surface microstructure of the nanoimprint is on the nanoscale. It is difficult to ensure the integrity of the surface microstructure during the replication process of a nanoimprint; thus, the optical properties of the optical functional texture will be affected. Optical functional microstructures on the micrometer scale have high precision and are commonly used in all types of light-trapping films and reflective films. Zhang et al. [11] processed a high-precision Fresnel lens texture on the cylindrical surface of a roller die and replicated a Fresnel lens array on the surface of polyethylene terephthalate (PET) film via a UV embossing method to obtain a high-precision concentrated functional surface texture. Jiang et al. [12] replicated holographic images on a high-precision roll die on the surface of a biaxially-oriented polypropylene (BOPP) film in a large area by means of hot embossing, and obtained a diffraction grating texture with superior accuracy.

To obtain improved optical properties, the precision of the surface texture film is required to be high, and the core technology using the embossing process is used to prepare a high-precision embossing mold [13]. Ultra-precision cutting with a diamond tool can produce microstructural surfaces with roughness values less than $10 \mathrm{~nm}$ [14]. Brinksmeier et al. [15] proposed a diamond microchiseling (DMC) technique for machining hexagon cube corner arrays with a structure size of $100 \mu \mathrm{m}$ on the surface of a nickel-plated mold, and its side surface roughness reached $S a=3 \mathrm{~nm}$, meeting the quality requirements of a mirror reflection. Kim et al. [16] used a single-crystal diamond tool to produce a micropyramid array with a height of $25 \mu \mathrm{m}$ from the surface of the copper-plated mold, and its lateral roughness reached $14.8 \mathrm{~nm}$.

Scholars have carried out research on optical functional structures at sub-wavelength and sub-millimeter scales. By using the wave theory of light analysis, it can be concluded that composite optical functional structures in the sub-wavelength range can reduce the refractive index of thin film materials, thereby reducing the reflection loss of solar cells [17]. Rahman et al. [8] laminated a layer of a flat film to the surface of crystalline silicon and then processed a fine conical texture $5 \mathrm{~nm}$ in height on the flat film using the ultra-precision ion etching method, which decreases the reflection loss of the composite structure crystalline silicon cells to below $1 \%$. However, the area of the prototype is only $0.5 \mathrm{~cm}^{2}$ due to the prohibitively high cost. It is currently still difficult to produce large-area optical functional textured films using the ion etching technique. In addition, the nanoembossing technique allows for the fabrication of nanoscale optical functional textured films over a large area, but the fabricated composite laminate structure of crystalline silicon cells only achieves mediocre light performance because of the low fabrication accuracy of the structure. Han et al. [18] laminated PVC-textured films to the smooth surface of crystalline silicon cells using the hot embossing method, which reduced the reflection loss of the crystalline silicon cells from $30 \%$ to approximately $15 \%$. Amalathas et al. [19] fabricated a regular inverted pyramidal textured film onto the smooth surface of the crystalline silicon cells at the nanoscale using the ultraviolet (UV) imprinting embossing technique, which lowered the reflection loss of the smooth surface crystalline silicon cells to approximately $14 \%$.

Based on geometrical optics analysis, sub-millimeter-scale light functional textured films can effectively reduce the reflection loss of solar cells. Dottermusch [20] et al. prepared sub-millimeter-scale tapered textures on monocrystalline silicon solar cells, which can reduce the reflection loss to about $8 \%$. Our previous research [21] also found that by laminating a sub-millimeter-scale optical functional texture film to a smooth surface crystalline silicon cell, as shown in Figure 1, the reflection loss of the cell can be reduced to $13 \%$. The embossing process can be used to prepare sub-millimeter-scale optical functional textured films with large area and low cost, and the dimensional accuracy and surface quality of sub-millimeter-scale microstructures can be better controlled. The prepared films have good optical properties. 


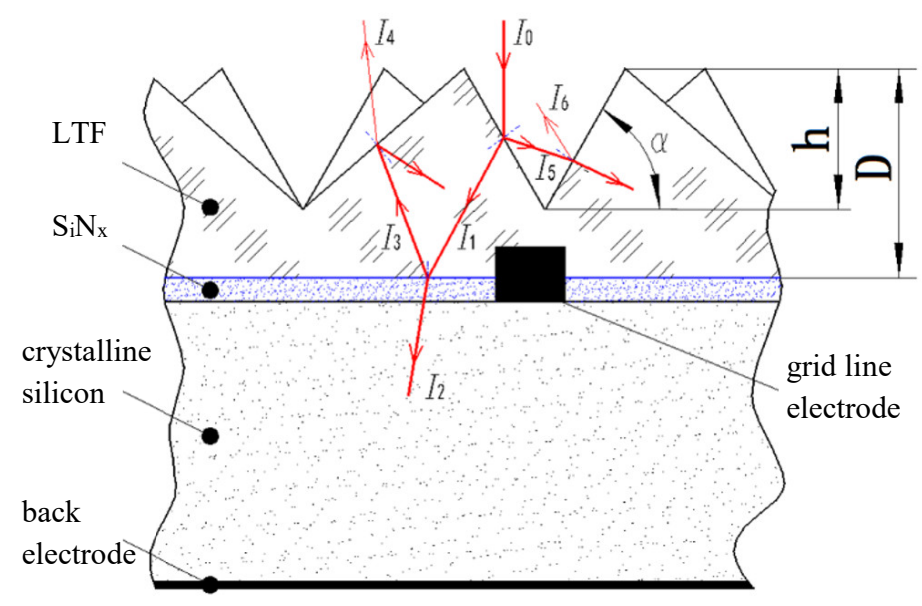

Figure 1. Composite laminate structure.

The processing accuracy of the original master mold has a great influence on the optical performance of the sub-millimeter-scale light functional textured film. In order to further reduce the reflectivity of the light functional textured film, it is an effective method to improve the processing accuracy of the mold. This paper studies how to improve the processing accuracy of the mold, and analyzes the effect of processing accuracy on the performance of the light functional textured film.

The innovations of this paper can be summarized as follows: (1) The influence of ultra-precision machining parameters of micrometer-scale microstructures on the accuracy of the original mold is studied; (2) a new parameter is defined to evaluate the effect of processing errors on the performance of optical functional textured films.

In this paper, according to the technical requirements of the light trapping film with a triangular pyramid, the processing precision of the original mold of the light trapping film (LTF) was formulated. The effects of cutting tools and cutting parameters on the quality of the original mold were experimentally studied. The area ratio of the retro-reflection was used to analyze the influence of the tool nose radius and exit burr on the effective optical functional area of the textured film, laying a foundation for the subsequent preparation of high performance light functional textured film.

\section{Technical Requirements for the Light-Trapping Texture of the Triangular Pyramid}

\subsection{Optical Functional Textured Film for Light-Trapping}

A light-trapping film can improve the absorption rate of its composite devices by modifying its surface microstructure. When the light hits the upper surface of the triangular pyramid texture, it can be refracted into the film several times, thus improving its transmittance. When the light is incident from the subsurface of the triangular pyramid texture film, it will be reflected from the inner surface of the triangular pyramid several times, so the light can be retro-reflected in parallel. To study how to improve the absorption rate of crystalline silicon cells, a research group [21] proposed a microscale triangular pyramidal trapping film and optimized its structural parameters, as shown in Figure 2. The light-trapping texture film is the basic unit of the two symmetrical pyramid structures. The individual right in triangular pyramid structure is the underside of the three sides of an isosceles triangle triangular pyramid. A single pyramid structure is a triangular pyramid whose base is an equilateral triangle and the three sides are isosceles triangles, and its surface triangular pyramid microstructure parameters are as follows: The bottom side $a=115 \mu \mathrm{m}$, and the included angle between two sides $\beta=70.5$. To prevent diffuse reflection of light on the optical functional texture surface, the side surface roughness of microtriangular pyramid must be less than $20 \mathrm{~nm}$. 


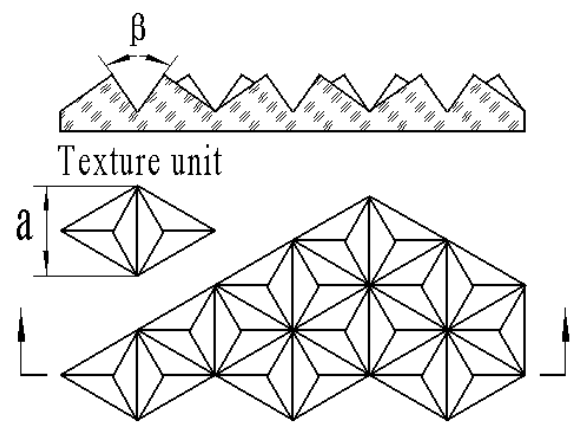

Figure 2. Triangular pyramid microstructure model.

\subsection{Light-Trapping Film Mold}

\subsubsection{Precision of the Size and Surface}

Embossing technology can be used to emboss the optical functional texture on the surface of the high-transmittance film. The embossing process is as follows: (1) The original mold of the positive pyramid texture is prepared via ultra-precision machining technology; (2) then, the working mold for replicating the inverted pyramid texture is prepared via precision electroforming processes [22]; and (3) finally, the positive pyramid texture is prepared on the surface of the highlighted transmittance film via hot embossing or UV imprinting. As various errors of the original mold are directly transmitted to the optical functional texture film, high requirements regarding the machining accuracy of the original mold are imposed [23-25]. According to the dimensional precision and surface roughness of the light-trapping film, via combination with the precision of electroforming and embossing, the size and surface precision of the microtriangular pyramid of the mold is determined as follows: The bottom side is $a=115 \pm 3 \mu \mathrm{m}$, the included angle between two sides is $\alpha=70.5^{\circ} \pm 0.05^{\circ}$, the surface roughness is $R a=10 \mathrm{~nm}$, and the dimensional deviation is less than $3 \%$. To achieve such a high machining quality, the forming process can effectively duplicate the shape of the cutter and ensure the dimensional accuracy of the finished product.

\subsubsection{Shape Precision}

When cutting the mold with the triangular pyramid texture, because the rounded corners of the tool nose will produce an arc transition at the bottom of the triangular pyramid, and burr will be generated at the edge of the triangular pyramid during processing, these shape errors will be copied to the light trapping film with triangular pyramid, affecting the effective optical functional area of the triangular pyramid texture film. As shown in the Figure 3a, the shadow area of the bottom of the unit texture of the mold and the orthographic projection of edges are invalid optical functional areas, and the width of the triangular pyramid edge burr projection is $W_{b}$. Figure $3 b$ shows that the arc radius $r_{\varepsilon}$ of the tool edge is the arc-invalid region of the EF. $k_{s}$ is defined as the ratio of the effective optical functional projection area of the triangular pyramid of the element to the area of the triangular pyramid bottom, i.e., $k_{S}$ is,

$$
k_{s}=1-\frac{\sum_{i=1}^{3 n} a_{i} \times r_{\varepsilon} \cos \frac{\alpha}{2}+\frac{\sqrt{3}}{3} \times \frac{\sum_{i=1}^{3 n} a_{i}}{3 n} \times \sum_{i}^{3 n} W_{b i}}{\frac{\sqrt{3} n}{4}\left(\frac{\sum_{i=1}^{3 n} a_{i}}{3 n}\right)^{2}}
$$

where $r_{\varepsilon}$ is the tool nose radius, $\alpha$ is the included angle between two sides, $W_{b}$ is the projection width of the triangular edge burr, $a$ is the bottom length of the unit triangular pyramid, and $n$ is the number of triangular pyramids. 

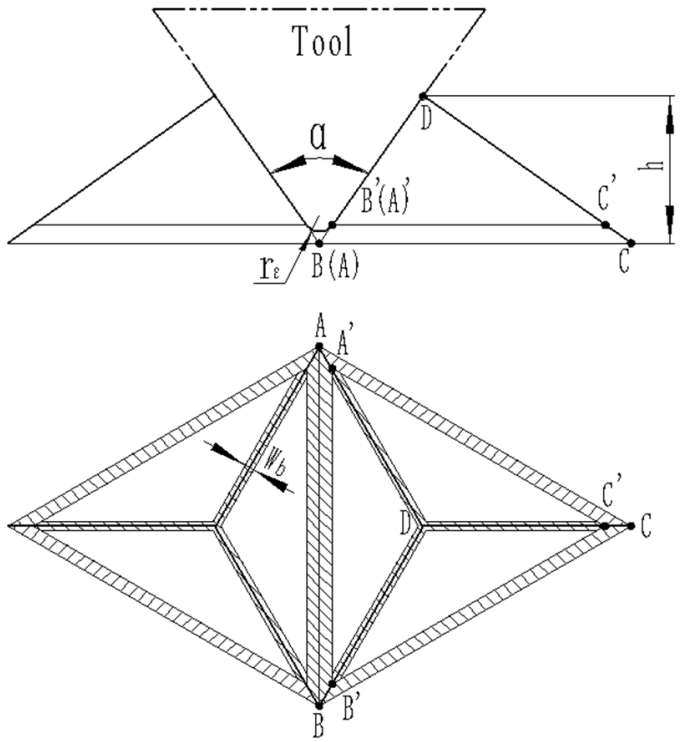

(a)

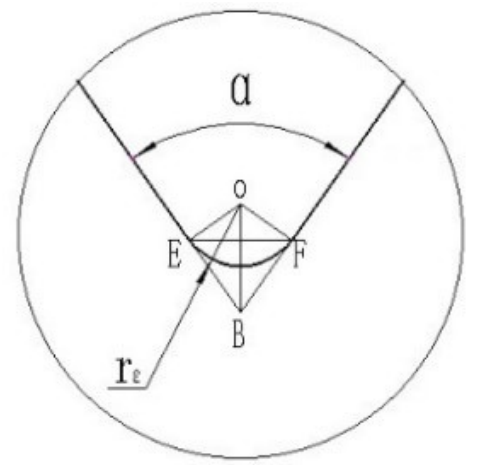

(b)

Figure 3. Invalid retro-reflection region: (a) Schematic diagram of the invalid retro-reflection area, (b) invalid area of the valley

\section{Cutting Experiment of the Mold}

\subsection{Equipment and Cutting Tools}

To avoid the machining errors caused by a change in the cutting depth of the tool, a 5-axis ultra-precision machining system (Moore Nanotech 350F, Moore Nanotechnology Systems Ltd., Swanzey, NH, USA) is adopted as the shaping method for planning. Its repeat positioning accuracy is $0.3 \mu \mathrm{m}$, and the positioning error has little effect on the size of the triangular pyramid. As shown in Figure $4 \mathrm{a}$, the work piece is installed on the vacuum clamp of the Z-axis, and a diamond tool with a large tool nose radius and a small tool nose radius is clamped at the left, and right in the tool holder, respectively. The datum plane of the texture is cut by a diamond tool with an enormous arc radius at the tip to eliminate the error of the datum plane caused by the installation. After obtaining the finishing datum plane, the tool holder rotates $180^{\circ}$ about axis B, the diamond tool nose processed with a V-groove is aligned with the work piece reference plane, and the principal cutting movement is conducted along the Y-axis. By stepping along the Z-axis of the tool holder, the stepper deep feeding movement of each $\mathrm{V}$-groove is realized. The $\mathrm{X}$-axis stepping motion can produce all parallel V-grooves in the $\mathrm{C} 1$ direction on the work piece surface. As shown in Figure $4 \mathrm{~b}$, when all V-grooves in the $\mathrm{C} 1$ direction are processed, the work piece rotates $60^{\circ}$ around the $\mathrm{C}$-axis to process the V-grooves in the $\mathrm{C} 2$ direction. When all $\mathrm{V}$-grooves in the $\mathrm{C} 2$ direction are processed and the $\mathrm{V}$-grooves in the $\mathrm{C} 3$ direction are processed by rotating $-120^{\circ}$ around the $\mathrm{V}$-axis, a complete triangular pyramid structure can be generated. By setting the diamond tool prior to the experiment, the tool tip of the three cutting directions can be nearly intersected at one point, and the error can meet the processing accuracy of the triangular pyramid texture. 


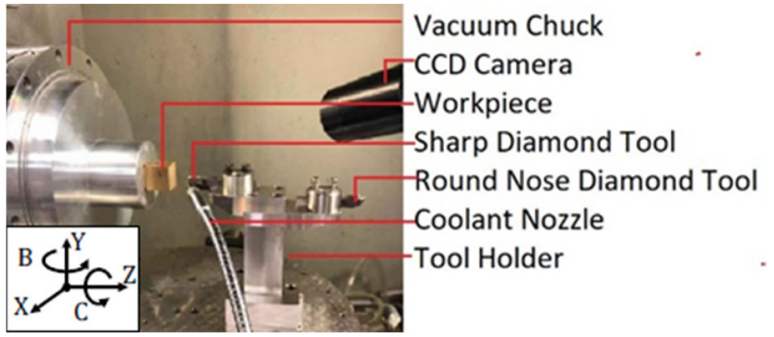

(a)

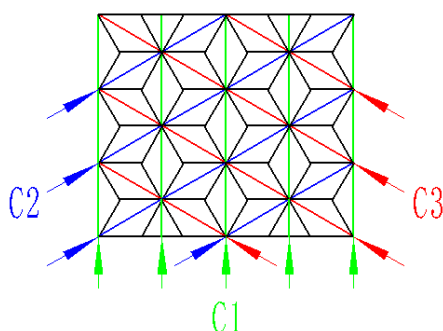

(b)

Figure 4. Ultra-precision single-crystal diamond cutting system: (a) Clamping mode of the workpiece and tool, (b) feed direction.

The forming method is adopted for precision planning. The angle of the forming planning tool nose is the same as that of the included angle between the two sides of the triangular pyramid texture. Selecting the rake angle of the tool as $0^{\circ}$ can reduce the influence of the tool shape on the shape precision of the forming method. In fine machining, the tool edge radius has a great influence on the machining quality [26]. Studies by Wu et al. [27] showed that the height of the burr increases as the tool edge radius increases. Based on the strength and wear rate of the tool, the tool edge radius of the sharp diamond tool is $0.1 \mu \mathrm{m}$. The precision of the forming surface can be improved via ultra-precision grinding of the diamond cutting edge. The increase in the tool nose radius will increase the area of the arc transition zone, thus affecting the area ratio of the retro-reflection of the original mold. Considering the wear rate of the diamond tool nose, the tool nose radius is selected to be $0.1 \mu \mathrm{m}$. The geometric parameters of the forming planning tool are reported in Table 1.

Table 1. Tool geometry parameters.

\begin{tabular}{ccccc}
\hline Rake Angle $\left({ }^{\circ}\right)$ & Clearance Angle $\left({ }^{\circ}\right)$ & Included Angle $\left({ }^{\circ}\right)$ & Tool Nose Aadius $(\mu \mathrm{m})$ & $\begin{array}{c}\text { Cutting-Edge } \\
\text { Radius }(\mu \mathrm{m})\end{array}$ \\
\hline 0 & 15 & 70.5 & 0.1 & 0.1 \\
\hline
\end{tabular}

To improve the surface accuracy of the triangular pyramidal texture mold, single-crystal diamond is selected as the tool material. The work piece material is composed of brass, which includes $60 \%$ copper $(\mathrm{Cu}), 0.7 \%$ tin $(\mathrm{Sn})$ and $39.3 \%$ zinc $(\mathrm{Zn})$, and its physical properties are given in Table 2 . The work piece size is $20 \mathrm{~mm} \times 20 \mathrm{~mm} \times 40 \mathrm{~mm}$. The friction coefficient $u=0.2$ between the diamond tool and brass was measured via a friction test. During the process of cutting, spray cooling is adopted at the top of the diamond tool to remove the cutting heat generated during the processing process, and the air-conditioning cooling system of the machining system is turned on to maintain the cutting environment temperature within $\pm 0.1^{\circ} \mathrm{C}$ to prevent thermal deformation.

Table 2. Material characteristics of the tool and workpiece.

\begin{tabular}{|c|c|c|c|c|c|c|}
\hline Material & $\begin{array}{l}\text { Young's Modulus } \\
\text { (GPa) }\end{array}$ & $\begin{array}{l}\text { Poisson's } \\
\text { Ratio }\end{array}$ & $\begin{array}{l}\text { Density } \\
\left(\mathrm{g} / \mathrm{cm}^{3}\right)\end{array}$ & $\begin{array}{c}\text { Thermal } \\
\text { Conductivity } \\
(\mathrm{W} / \mathrm{m} \cdot \mathrm{K})\end{array}$ & $\begin{array}{l}\text { Specific Heat } \\
(\mathrm{J} /(\mathbf{k g} \cdot \mathrm{K}))\end{array}$ & $\begin{array}{l}\text { Hardness } \\
\text { (HB) }\end{array}$ \\
\hline $\begin{array}{l}\text { Single } \\
\text { diamond }\end{array}$ & 960 & 0.2 & 3.5 & 2000 & 507.9 & 8000 \\
\hline Brass & 105 & 0.324 & 8.4 & 104.7 & 374 & 69.3 \\
\hline
\end{tabular}

\subsection{Selection of the Cutting Parameters}

The maximum moving speed of the Y-axis of the selected 5-axis ultra-precision machining system is $1500 \mathrm{~mm} / \mathrm{min}$, and the cutting speed is $1000 \mathrm{~mm} / \mathrm{min}$, considering the stability and flutter of the 
machine tool and other factors. According to the merchant [28], the expression of the principal cutting force can be derived from Equation (2),

$$
F_{y}=\frac{\tau_{s} a_{w} d_{c} \cos \left(\beta_{e}-\gamma\right)}{\sin \phi \cos \left(\phi+\beta_{e}-\gamma\right)}
$$

where $\tau_{s}$ is the shear stress, $a_{w}$ is the cutting width, $d_{c}$ is the uncut chip thickness, $\beta_{e}$ is the frictional angle, $\gamma$ is the rake angle, and $\Phi$ is the shear angle.

The Z-axis cutting depth was cut using stepper cutting, as shown in Figure 5. In the cases of other cutting parameters, with an increase in uncut chip thickness $d c$, the principal cutting force and burr height increase gradually [29]. Considering that the diamond tool nose radius and the cutting-edge radius are both $0.1 \mu \mathrm{m}$, the principal cutting force is large, which may cause the tool to be microscopically cracked. It is calculated using formula (2) that the uncut chip thickness $d c$ should not exceed $6 \mu \mathrm{m}$. According to the angle included between the two sides of the unit triangular pyramid, the step depth $\Delta Z 1$ of the tool along the Z-axis during roughing is $10 \mu \mathrm{m}$. When finishing, the cutting depth is reduced, the surface quality is better, and the burr size is smaller. However, as the cutting depth is further reduced, the cutting process changes to a plowing process, no chip is generated, and the surface quality worsens [27]. Under a constant cutting depth, the smaller the cutting speed is, the larger the shear strain $\varepsilon$ is, and it is more likely that a plowing phenomenon occurs [30].

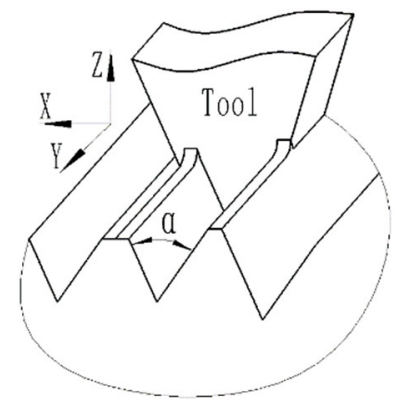

(a)

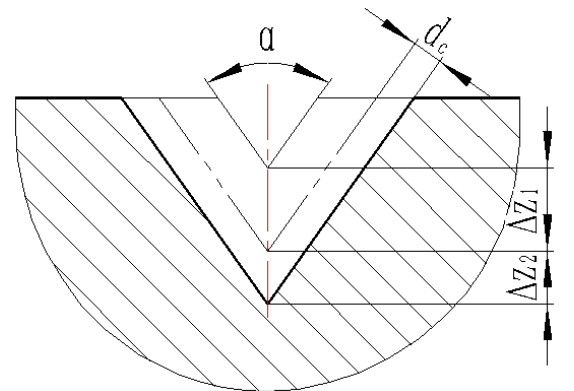

(b)

Figure 5. Stepped cutting in the Z-axis: (a) V-groove cutting schematic diagram, (b) Stepper deep feed.

To avoid surface quality degradation caused by the phenomenon of plowing, orthogonal cutting tests under different uncut chip thicknesses were performed, and plowing phenomena were observed. It is concluded that the plowing phenomenon begins when the uncut chip thickness $d c$ starts at $1 \mu \mathrm{m}$, and the surface roughness begins to deteriorate. The step depth $\Delta Z 2$ of the finishing tool along the $\mathrm{Z}$-axis is $2 \mu \mathrm{m}$. According to the length of the bottom edge of the triangular pyramid and the included angle between two sides, the height of the triangular pyramid is $47.2 \mu \mathrm{m}$. For each V-groove, the step depth of the tool along the Z-axis is $10 \mu \mathrm{m}, 10 \mu \mathrm{m}, 10 \mu \mathrm{m}, 10 \mu \mathrm{m}, 5.2 \mu \mathrm{m}$, and $2 \mu \mathrm{m}$.

\subsection{Quality Inspection of the Mold}

\subsubsection{Surface Roughness}

The surface roughness of the triangular pyramid texture mold will directly affect the optical function of the light-trapping film. A Mitutoyo Formtracer c-5000 (Mitutoyo, Kawasaki, Japan) stylus profilometer was used to measure the surface roughness Ra of the triangular pyramidal mold. As shown in Figure 6a, the work piece is mounted on a rotary table and the work piece is placed obliquely to ensure that the side of the triangular pyramid is in a horizontal position, thereby reducing the measurement error of the roughness. To evaluate the surface quality of the triangular pyramidal texture unit at different processing times, three different positions are selected as the sampling area, as shown in Figure 6b: The diamond tool cut-in area 1, the middle cut 2 and the diamond cutter cut-out 
area 3. As shown in Figure 6c, each of the sampling regions measures six triangular pyramid units, and each pyramid unit measures the surface roughness values of the middle and lower portions of the three sides. The roughness curve obtained on the typical side is shown in Figure $6 \mathrm{~d}$. The surface roughness $\mathrm{Ra}$ is up to $8 \mathrm{~nm}$. The roughness measured on 54 sides is averaged, as reported in Table 3 , and the average surface roughness $\mathrm{Ra}$ is up to $9.2 \mathrm{~nm}$, meeting the surface roughness requirements of the original mold.

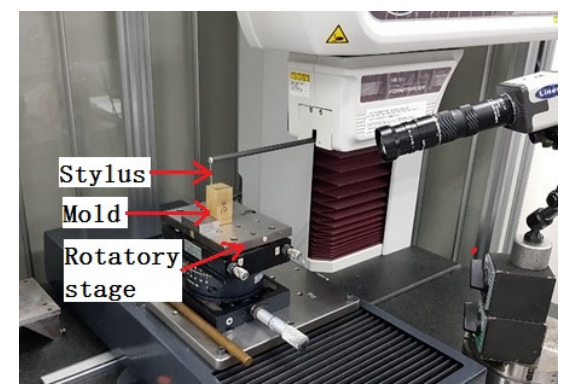

(a)

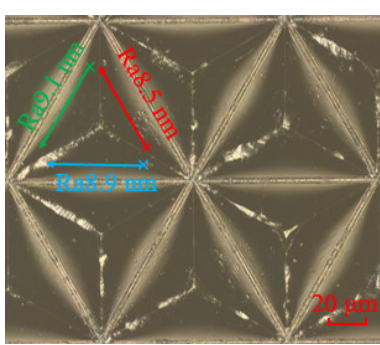

(c)

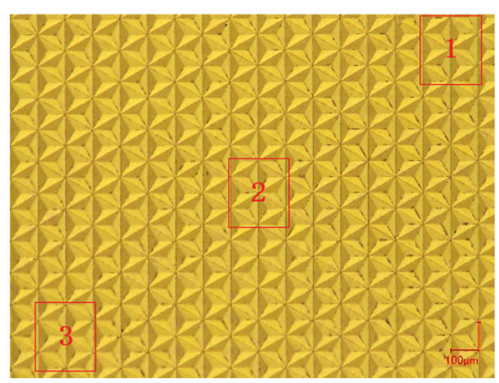

(b)

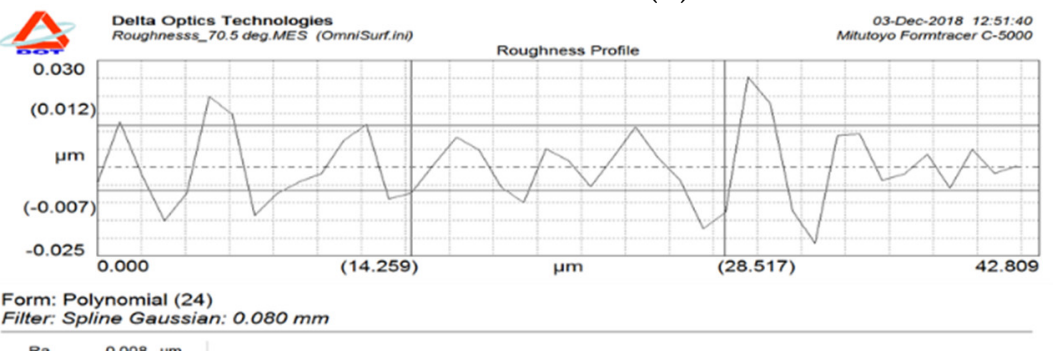

(d)

Figure 6. Surface roughness measured by a stylus profilometer: (a) Measuring conditions, (b) area of measurement, (c) measuring position, (d) roughness value.

Table 3. Measurement of the triangular pyramid microstructure size and roughness.

\begin{tabular}{cccccc}
\hline \multirow{2}{*}{ Sampling Area } & \multicolumn{2}{c}{ Triangular Pyramid Edge Length } & \multicolumn{2}{c}{ Triangular Pyramid Height } & $\begin{array}{c}\text { Roughness } \\
(\mathbf{n m})\end{array}$ \\
\cline { 2 - 5 } & Mean Value $(\mu \mathrm{m})$ & Deviation & Mean Value $(\boldsymbol{\mu m})$ & Deviation & $2.82 \%$ \\
\hline 1 & 113.41 & $-1.38 \%$ & 51.41 & $-0.76 \%$ & 9.5 \\
2 & 114.51 & $-0.42 \%$ & 49.62 & $1.48 \%$ & 9.3 \\
Mean value & 113.41 & $-1.38 \%$ & 50.74 & $1.18 \%$ \\
\hline
\end{tabular}

\subsubsection{Dimensional Accuracy}

The triangular pyramid microstructure was measured via laser scanning confocal microscopy (VK-X100K, KEYENCE, Osaka, Japan). The length of the bottom edge of 18 triangular pyramids and the height of 6 triangular pyramids were measured in the sampling area at the three positions in Figure $6 \mathrm{~b}$. During the cutting process of the mold, due to the plastic deformation of the material and the existence of processing errors, the processed optical functional texture is not perfect. There are often defects, such as burrs and deformations, and the purpose of this article is to minimize these defects. The average value and deviation were calculated, as reported in Table 3. It can be concluded that the triangular pyramid microstructure size error is approximately $1 \mu \mathrm{m}$, the maximum dimension deviation is only $2.82 \%$ (less than the required $3 \%$ ), and the included angle between two sides in the three directions is less than $0.05^{\circ}$, compared with the technical requirement of $70.5^{\circ}$. The actual machining contour of the included angle between two sides is highly consistent with the ideal machining contour. The dimensional accuracy of the triangular pyramid unit in the middle portion of the work piece is higher, which may be the higher stability of the central region. 


\subsubsection{The Evaluation of the Area Ratio of the Retro-Reflection}

As shown in Figure 7a, in the six triangular pyramid elements in the sampling area, the six inner edges of the contrast are found; the shape integrity of the edges 1,2 and 3 is always better than that of the edges 4, 5 and 6 . The possible reasons are analyzed as follows. When cutting in the C1 direction, the cutting is continuous, the cutting state is stable and the six edges are no longer formed. When cutting in the C2 direction, the cutting is no longer continuous; rather, it is interrupted, forming edges 1 and 4 , in which edge 4 is formed by the tool at the cut-out and edge 1 is formed by the tool at the cut-in. When cutting in the C3 direction, edges 2, 3 and 5, 6 are formed, in which edges 5 and 6 are formed at the cutting edge of the tool and edges 2 and 3 are formed at the cutting point of the tool. Since the edge of the cut-out can easily form the exit burr, edges 1,2, and 3 at the cut-in are better than edges 4,5 , and 6 of the cut-out. The $W_{\mathrm{b}}$-generated burr projection width on edges 4,5 and 6 was an invalid optical functional area.

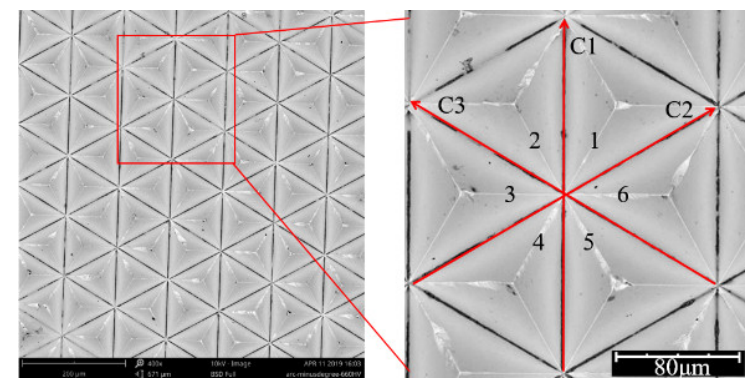

(a)

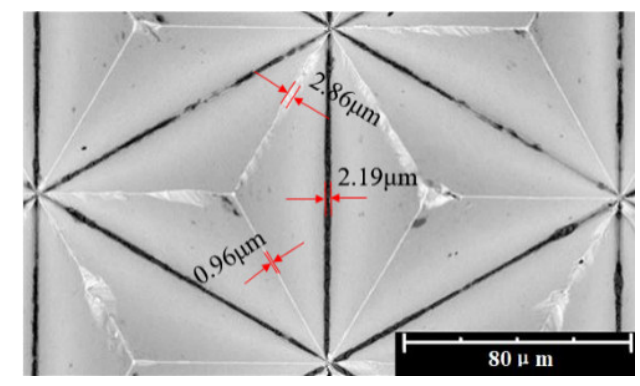

(b)

Figure 7. SEM (scanning electron microscope) of the burr and invalid zone: (a) Edge burrs, (b) Measurement of the invalid zone of the texture unit.

Through the above analysis, it is found that there are 6 edges for the texture unit, and the number $\mathrm{m}$ of the edges of the exit burrs is only 3. The width of the valley arc and the projection width of the burr are measured, as shown in Figure $7 \mathrm{~b}$. Calculating its arithmetic means, the results are presented in Table 4. For the texture unit, $k_{s}=93.5 \%$ is derived from the definition of the area ratio of the retro-reflection. By selecting a high-precision machining system and analyzing and optimizing the cutting tools and cutting boundaries, the original mold obtained meets the retro-reflective requirements of the optical functional texture of the triangular pyramid.

Table 4. Arc width of the valley bottom and burr projection width.

\begin{tabular}{cccc}
\hline \multirow{2}{*}{ Sampling Area } & $\begin{array}{c}\text { Arc Width of the Valley } \\
\text { Bottom EF }\end{array}$ & $\begin{array}{c}\text { Edge Burr width at the } \\
\text { Cut-in }\end{array}$ & $\begin{array}{c}\text { Edge Burr Width at the } \\
\text { Cut-out }\end{array}$ \\
\cline { 2 - 4 } & Mean Value $(\mu \mathrm{m})$ & Mean Value $(\mu \mathrm{m})$ & Mean Value $(\mu \mathrm{m})$ \\
\hline 1 & 2.75 & 0.96 & 2.13 \\
2 & 2.64 & 0.97 & 2.08 \\
3 & 2.74 & 0.97 & 2.11 \\
Mean value & 2.71 & 0.97 & 2.11 \\
\hline
\end{tabular}

\section{Conclusions}

(1) According to the precision and preparation process of the triangular pyramid optical functional texture film, technical requirements, including the shape, size and surface roughness of the original mold are determined. An ultra-precision machining system is used to both design the tool geometry according to the machining plan and optimize the cutting boundaries. Through the cutting experiment, an original mold with a surface roughness of Ra less than $10 \mathrm{~nm}$ and a surface morphology that satisfies the requirements of the optical functional texture is obtained. 
(2) Low-speed forming planning technology is adopted in the ultra-precision machining system to avoid large fluctuations in the cutting force caused by the change in the cutting thickness, and the processing precision of the fine structure can be strengthened.

(3) As the independent arrangement of the unit structure on the surface functional texture of the part, the unit structure has intermittent cutting. There will be fine burrs at the cutting end of each unit structure. The effect of the burr on the functional texture surface quality can be effectively reduced by optimizing the cutting tool, cutting material and cutting parameters.

(4) The optical properties of the optical functional texture can be indirectly evaluated by analyzing the distribution of the edge burr and calculating the area ratio of the retro-reflection of the triangular pyramidal texture unit of the processed mold.

Author Contributions: Conceptualization, Z.X.; methodology, Z.X.; formal analysis, H.L. and J.P.; experiments, H.L.; data curation, F.Z.; writing, H.L.; revision, Z.X. and J.P. All authors have read and agreed to the published version of the manuscript.

Funding: This work was supported by the National Natural Science Foundation of China (Grant No. 51676085).

Acknowledgments: The authors would like to thank the Singapore Institute of Manufacturing Technology, which provided support in performing the experiments.

Conflicts of Interest: The authors declare no conflict of interest. The funders had no role in the design of the study; in the collection, analyses, or interpretation of data; in the writing of the manuscript, and in the decision to publish the results.

\section{References}

1. Hsu, Q.C.; Chen, Y.L. Fabrication of 3D random microlens array composite optical film with self-assembly. Int. J. Adv. Manuf. Technol. 2015, 76, 247-254. [CrossRef]

2. Kang, S.; Wang, J.; Zhang, S.; Zhao, C.; Wang, G.; Cai, W.; Zhang, H. Plasma-etching enhanced titanium oxynitride active phase with high oxygen content for ambient electrosynthesis of ammonia. Electrochem. Commun. 2019, 100, 90-95. [CrossRef]

3. Wang, Y.; Zhang, M.; Lai, Y.; Chi, L. Advanced colloidal lithography: From patterning to applications. Nano Today 2018, 22, 36-61. [CrossRef]

4. Yi, P.; Deng, Y.; Shu, Y.; Peng, L. Experimental studies on a novel roll-to-roll powder hot embossing for large-area fabrication of micropyramid arrays on polymers. J. Micromech. Microeng. 2018, 28. [CrossRef]

5. Velten, T.; Schuck, H.; Haberer, W.; Bauerfeld, F. Investigations on reel-to-reel hot embossing. Int. J. Adv. Manuf. Technol. 2010, 47, 73-80. [CrossRef]

6. Bender, M.; Otto, M.; Hadam, B.; Vratzov, B.; Spangenberg, B.; Kurz, H. Fabrication of nanostructures using a UV-based imprint technique. Microelectron. Eng. 2000, 53, 233-236. [CrossRef]

7. Huang, Y.-Y.; Ke, K.-C.; Yang, S.-Y. Fabrication of large-area V-groove microstructures using gasbag-pressuring edge-irradiating UV imprinting. Microsyst. Technol. 2018, 25, 811-817. [CrossRef]

8. Rahman, A.; Ashraf, A.; Xin, H.; Tong, X.; Sutter, P.; Eisaman, M.D.; Black, C.T. Sub-50-nm self-assembled nanotextures for enhanced broadband antireflection in silicon solar cells. Nat. Commun. 2015, 6, 5963. [CrossRef] [PubMed]

9. Diao, Z.; Hirte, J.; Chen, W.; Spatz, J.P. Inverse Moth Eye Nanostructures with Enhanced Antireflection and Contamination Resistance. ACS Omega 2017, 2, 5012-5018. [CrossRef]

10. Cirino, G.A.; Granado, R.M.; Mohammed-Brahim, T.; Jasinevicius, R.G. Assessment of replication fidelity of optical microstructures by hot embossing. Int. J. Adv. Manuf. Technol. 2016, 88, 303-316. [CrossRef]

11. Zhang, X.; Huang, R.; Liu, K.; Kumar, A.S.; Shan, X. Rotating-tool diamond turning of Fresnel lenses on a roller mold for manufacturing of functional optical film. Precis. Eng. 2018, 51, 445-457. [CrossRef]

12. Jiang, M.; Lin, S.; Jiang, W.; Pan, N. Hot embossing holographic images in BOPP shrink films through large-area roll-to-roll nanoimprint lithography. Appl. Surf. Sci. 2014, 311, 101-106. [CrossRef]

13. Gao, X.; Li, Y.; Kong, Q.; Tan, Q.; Li, C. Uniform concentrating design and mold machining of Fresnel lens for photovoltaic systems. Int. J. Adv. Manuf. Technol. 2018. [CrossRef]

14. Zhang, S.J.; To, S.; Wang, S.J.; Zhu, Z.W. A review of surface roughness generation in ultra-precision machining. Int. J. Mach. Tools Manuf. 2015, 91, 76-95. [CrossRef] 
15. Brinksmeier, E.; Gläbe, R.; Flucke, C. Manufacturing of molds for replication of micro cube corner retroreflectors. Prod. Eng. 2008, 2, 33-38. [CrossRef]

16. Kim, C.E.; Jeon, E.; Je, T.J.; Kang, M.C. Machining Characteristics of Micro Structure using Single-Crystal Diamond Tool on Cu-plated Mold. J. Korean Powder Metall. Inst. 2015, 22, 169-174. [CrossRef]

17. Zhang, X.; Lan, P.; Lu, Y.; Li, J.; Xu, H.; Zhang, J.; Lee, Y.; Rhee, J.Y.; Choy, K.L.; Song, W. Multifunctional antireflection coatings based on novel hollow silica-silica nanocomposites. ACS Appl. Mater. Interfaces 2014, 6, 1415-1423. [CrossRef]

18. Han, K.S.; Lee, H.; Kim, D.; Lee, H. Fabrication of anti-reflection structure on protective layer of solar cells by hot-embossing method. Sol. Energy Mater. Sol. Cells 2009, 93, 1214-1217. [CrossRef]

19. Amalathas, A.P.; Alkaisi, M.M. Efficient light trapping nanopyramid structures for solar cells patterned using UV nanoimprint lithography. Mater. Sci. Semicond. Process. 2017, 57, 54-58. [CrossRef]

20. Dottermusch, S.; Schmager, R.; Klampaftis, E.; Paetel, S.; Kiowski, O.; Ding, R.; Richards, B.S.; Paetzold, U.W. Micro-cone textures for improved light in-coupling and retroreflection-inspired light trapping at the front surface of solar modules. Prog. Photovolt. Res. Appl. 2019, 27, 593-602. [CrossRef]

21. Xu, Z.; Yang, X.; Huang, Z.; Liu, J.; Wang, S.; Fang, F. Research of photoelectric characteristics of crystallline silicon composite cell with smooth surface and light trpping film. Acta Energ. Sol. Sin. 2017, 12, 11.

22. Qu, N.S.; Qian, W.H.; Hu, X.Y.; Zhu, Z.W. Preparation of a Microprism Ni-Ceo2Nanocomposite Mold by Electroforming. Mater. Manuf. Process. 2014, 29, 37-41. [CrossRef]

23. Ong, N.S.; Koh, Y.H.; Fu, Y.Q. Microlens array produced using hot embossing process. Microelectron. Eng. 2002, 60, 365-379. [CrossRef]

24. Liu, Y.; Qiao, Z.; Qu, D.; Wu, Y.; Xue, J.; Li, D.; Wang, B. Experimental Investigation on Form Error for Slow Tool Servo Diamond Turning of Micro Lens Arrays on the Roller Mold. Materials (Basel) 2018, 11, 1816. [CrossRef]

25. Cheung, C.F.; Lee, W.B. Characterisation of nanosurface generation in single-point diamond turning. Int. J. Mach. Tools Manuf. 2001, 41, 851-875. [CrossRef]

26. Yang, D.; Xiao, X.; Liang, X. Analytical modeling of residual stress in orthogonal cutting considering tool edge radius effect. Int. J. Adv. Manuf. Technol. 2019, 103, 2965-2976. [CrossRef]

27. Wu, X.; Li, L.; He, N.; Hao, X.; Yao, C.; Zhong, L. Investigation on the ploughing force in microcutting considering the cutting edge radius. Int. J. Adv. Manuf. Technol. 2016, 86, 2441-2447. [CrossRef]

28. Merchant, M.E. Mechanics of the Metal Cutting Process. I. Orthogonal Cutting and a Type 2 Chip. J. Appl. Phys. 1945, 16, 267-275. [CrossRef]

29. Fang, F.Z.; Liu, Y.C. On minimum exit-burr in micro cutting. J. Micromech. Microeng. 2004, 14, 984-988. [CrossRef]

30. Luo, S.; Bayesteh, A.; Ko, J.; Dong, Z.; Jun, M.B. Numerical simulation of chip ploughing volume in micro ball-end mill machining. Int. J. Precis. Eng. Manuf. 2017, 18, 915-922. [CrossRef] 